\title{
Avoiding sternotomy in repeat coronary artery bypass grafting: Feasibility, safety, and mid-term outcome of the transabdominal off-pump technique using the right gastroepiploic artery
}

\author{
Giuseppe Tavilla, MD, PhD, ${ }^{\mathrm{a}, \mathrm{b}}$ and Eline F. Bruggemans, $\mathrm{MSc}^{\mathrm{a}}$
}

Objectives: Repeat sternotomy is associated with a substantial risk of cardiovascular injury. We evaluated the feasibility and clinical outcome of a transabdominal approach without sternotomy and without cardiopulmonary bypass in repeat coronary artery bypass grafting, using the right gastroepiploic artery to graft vessels of the inferior wall of the heart.

\begin{abstract}
Methods: From July 1999 to October 2010, 22 patients presenting with only right coronary artery disease underwent reoperation using the transabdominal approach and a skeletonized gastroepiploic artery graft. In all patients but 1, a patent graft to the anterior wall was present. The mean EuroSCORE was $6.4 \pm 2.5$.
\end{abstract}

Results: All patients had adequate surgical exposure, and no conversion to sternotomy or the use of cardiopulmonary bypass was required. There was no in-hospital mortality. Hospital morbidity included pneumothorax in 1 patient and atrial fibrillation in 2 patients. The median hospital stay was 5 days. Follow-up was complete, and the median follow-up time was 6 years. There were 2 late deaths. Four patients experienced recurrence of angina, of whom three required percutaneous coronary intervention. The estimated freedom from major cardiovascular and cerebrovascular events rate was $70.2 \%$ at 6 years. Fourteen patients underwent an exercise stress test at a median interval of 2 years, with all showing no signs of myocardial ischemia.

Conclusions: Transabdominal off-pump coronary artery bypass grafting using the right gastroepiploic artery is a safe and effective procedure with low in-hospital mortality and morbidity and favorable mid-term outcome. In redo operations, this technique excludes the risk of cardiovascular injury. ( $\mathrm{J}$ Thorac Cardiovasc Surg 2012;144:124-9)

Reoperation for coronary artery bypass grafting (CABG) can be performed with acceptable mortality and morbidity but is still a surgical challenge. Repeat median sternotomy is associated with a significant risk of cardiovascular injury, which, in turn, carries a substantial risk of in-hospital death. The structures likely to be injured during either the sternal division itself or during dissection include the right ventricle, innominate vein, aorta, saphenous vein grafts (SVGs), and internal thoracic artery (ITA) grafts. Patients with patent ITA grafts are at particular risk, with an incidence of injury to the ITA of $4.9 \%$ to $5.3 \% .^{1-3}$ Injury to an ITA has been associated with a mortality rate of $17.9 \%{ }^{3}$

Because the technical challenge of resternotomy in patients with patent ITA grafts is well recognized, several less-invasive alternatives have been advocated. In

From the Department of Cardiothoracic Surgery, ${ }^{a}$ Leiden University Medical Center, Leiden, The Netherlands; and Department of Cardiothoracic Surgery, ${ }^{\mathrm{b}}$ University Medical Center St. Radboud, Nijmegen, The Netherlands

Disclosures: Authors have nothing to disclose with regard to commercial support.

Received for publication May 2, 2011; revisions received June 24, 2011; accepted for publication July 27, 2011; available ahead of print Sept 1, 2011.

Address for reprints: Giuseppe Tavilla, MD, PhD, Department of Cardiothoracic Surgery, University Medical Center St Radboud, PO Box 9101, 6500 HB Nijmegen, The Netherlands (E-mail: G.Tavilla@ctc.umcn.nl).

$0022-5223 / \$ 36.00$

Copyright $($ c 2012 by The American Association for Thoracic Surgery doi:10.1016/j.jtcvs.2011.07.060 particular, when the culprit vessels are located in one region, a small and directed incision without cardiopulmonary bypass $(\mathrm{CPB})$ could be used. Left thoracotomy has been described as a suitable and safe technique in patients who need grafting to the lateral wall of the left ventricle. ${ }^{4,5}$ When the right coronary artery (RCA) or the right posterior descending artery (PDA) is the only vessel involved, a small laparotomy with or without a T-shaped incision of the lower third of the sternum has been shown to be a useful alternative. ${ }^{6-8}$

Despite the first successful experiences, reports of redo CABG without sternotomy and without CPB remain limited. In this study, we describe a 10-year experience with the transabdominal off-pump technique using the right gastroepiploic artery (GEA) involving 22 redo patients, emphasizing the feasibility and safety of this approach and its mid-term clinical outcomes.

\section{METHODS \\ Patient Population}

From July 1999 to October 2010, 22 patients with previous CABG underwent a reoperation with the transabdominal off-pump CABG technique using an in-situ GEA. Surgery was performed by 1 surgeon (G.T.) at two institutions in two consecutive periods, following the same protocol. During these periods, all patients requiring repeat $\mathrm{CABG}$ with isolated highgrade stenosis $(>75 \%)$ or occlusion of the RCA or the PDA and significant myocardial ischemia confined to the inferior wall of the heart were selected 


$$
\begin{aligned}
& \text { Abbreviations and Acronyms } \\
& \begin{aligned}
\text { CABG } & =\text { coronary artery bypass grafting } \\
\text { CPB } & =\text { cardiopulmonary bypass } \\
\text { GEA } & =\text { gastroepiploic artery } \\
\text { ITA } & =\text { internal thoracic artery } \\
\text { MACCE } & =\text { major cardiovascular or } \\
& \text { cerebrovascular event } \\
\text { PCI } & =\text { percutaneous coronary intervention } \\
\text { PDA } & =\text { posterior descending artery } \\
\text { RCA } & =\text { right coronary artery } \\
\text { SVG } & =\text { saphenous vein graft }
\end{aligned}
\end{aligned}
$$

for this technique. The patients were not considered proper candidates for percutaneous coronary intervention (PCI). The exclusion criteria for the technique included previous upper abdominal surgery and the target vessel being the posterolateral branch of the RCA. The patients were not excluded on the basis of age or major comorbidities.

All patients had a patent graft to the anterior wall of the heart but 1 (Table 1). This patient received single venous grafting to the marginal branch and aortic valve replacement during the primary procedure performed elsewhere. In an attempt to control a bleeding event at the aortotomy, the ostium of the RCA was accidentally closed. The patient experienced a posterior wall myocardial infarction and postoperative angina (patient 16; Table 1).

The demographic and preoperative characteristics of the patients are summarized in Table 2. The mean age was $64.5 \pm 8.1$ years. There were 21 men. Two patients underwent a second reoperation. The mean interval from the previous operation to the index repeat $\mathrm{CABG}$ was $11.6 \pm 5.9$ years. The mean additive EuroSCORE was $6.4 \pm 2.5$, with 14 patients at high risk (additive EuroSCORE of $\geq 6$ ). The mean logistic EuroSCORE was $7.9 \pm 6.8$. The study was approved with a waiver of consent by the ethics committee of each institution.

\section{Surgical Technique}

The patients were placed in the standard supine position. A dry air warming system was placed around each patient to preserve a normal body temperature. Above the xiphoid, an $8-$ to $10-\mathrm{cm}$ median incision was made on the scar of the previous sternotomy. This incision was long enough to excise the xiphoid process, position a standard sternal retractor, obtain adequate exposure of the inferior wall of the heart, and allow for easy access to the upper abdomen for harvesting the GEA, making an additional lower sternotomy superfluous in all cases. The diaphragmatic surface of the heart was then dissected free from the diaphragm to facilitate exposure of the inferior wall of the heart. The RCA and PDA were identified to choose the target coronary artery for the anastomosis. Dissection of adhesions was limited, just enough to permit exposure of the target coronary artery. The remaining adhesions were kept intact, because such adhesions act as stabilizers.

At this stage, the peritoneum was opened, the stomach was pulled gently out of the abdomen, and harvesting of the GEA was performed in a skeletonized manner. In the first patients, the GEA was skeletonized using hemoclips to separate its branches from the stomach and omentum. Thereafter, an ultrasonic scalpel (Harmonic Scalpel; Ethicon, Johnson \& Johnson, New Brunswick, NJ) was used. After heparinization $(1.5 \mathrm{mg} / \mathrm{kg})$, the distal part of the GEA was divided and 3 to $4 \mathrm{~mL}$ of a nitroprusside hydrochloride solution $(20 \mathrm{mg}$ of nitroprusside hydrochloride diluted in $50 \mathrm{~mL}$ of physiologic saline) was injected intraluminally to relieve spasm. A hemoclip was placed at the distal end of the GEA; the graft was put in a warm gauze imbedded in dilute nitroprusside and was then placed back into the abdominal cavity, together with the stomach. This handling of the GEA allowed the artery to vasodilate both by the pharmacologic effect of the nitroprusside and by its own blood pressure.

Next, a hole in the right hemidiaphragm was made to route the GEA intrapericardially. The site of the opening was chosen according to the intended location of the anastomosis. The GEA was always routed antegastrically and in front of the liver. Once the GEA was placed intrapericardially, an Octopus suction stabilizer (Medtronic, Minneapolis, MN) was fixed cranially on the retractor, and the suction branches were placed as close as possible to the target coronary artery. The suction device acted not only as a coronary stabilizer, but also allowed us to push back and to pull up the inferior wall of the heart for an optimal surgical view. In patients with deep chests, exposure of the surgical field was improved by either suturing the diaphragm to the caudal end of the skin incision or placing a deep abdominal retractor, pulling caudally the diaphragm, liver, and other abdominal organs.

An incision of approximately $4 \mathrm{~mm}$ in the target coronary artery was made, and an intracoronary shunt was placed whenever possible. The anastomosis was performed with a continuous 8-0 or 7-0 polypropylene suture on the beating heart. After completion of the anastomosis, $1 \mathrm{~cm}^{3}$ of fibrin glue (Tissucol; Baxter, Deerfield, Ill) was injected around the anastomosis to avoid any torsion of the GEA graft. Heparin was antagonized with protamine (half the dose of the administered heparin). At the end of the procedure, a small drainage tube was placed into the pericardium, and the incision was routinely closed.

\section{Data Collection}

The preoperative, operative, and in-hospital outcome variables were extracted from the patients' medical records and entered into a dedicated database on the discharge of the patients from the hospital. Follow-up information was obtained from the attending cardiologists as a part of routine care and by regular telephone interviews with the survivors. The questions addressed cardiac-related rehospitalizations and reinterventions, the patients' Canadian Cardiovascular Society class, stroke, and, if applicable, the cause and date of death. For the patients who underwent follow-up coronary angiography or repeat revascularization, the medical reports were reviewed, with special attention to GEA patency. The results of exercise stress testing were examined, if conducted. A major cardiovascular or cerebrovascular event (MACCE) was defined as all-cause death, new myocardial infarction, repeat revascularization, or stroke. The closing interval for follow-up was October 2010 to December 2010.

\section{Statistical Analysis}

Continuous variables are presented as the mean \pm standard deviation or as the median and range, as appropriate. Categorical variables are expressed as the frequencies and percentages. Estimates of overall survival and freedom from MACCE were obtained using the Kaplan-Meier method. All statistical analyses were performed using the Statistical Package for Social Sciences software program for Windows, version 16.0.2 (SPSS, Chicago, Ill).

\section{RESULTS \\ Operative Characteristics}

The GEA was suitable as a conduit in all patients, independent of age, peripheral arterial disease, and diabetes mellitus. The graft was anastomosed to the PDA in 12 patients and to the RCA in 9 (Table 1). In 1 patient (patient 4), the GEA was grafted to a patent SVG between the PDA and the posterolateral branch of the RCA. Thrombus endarterectomy of the PDA was necessary in 1 patient (patient 5) and a concomitant thrombus endarterectomy of a carotid artery in another patient (patient 3). The mean 
TABLE 1. First and redo operative characteristics and outcomes

\begin{tabular}{|c|c|c|c|c|c|c|c|c|c|c|}
\hline $\begin{array}{l}\text { Pt } \\
\text { no. }\end{array}$ & $\begin{array}{c}\text { Age } \\
(y)\end{array}$ & $\begin{array}{l}\text { Previous } \\
\text { CABG (n) }\end{array}$ & $\begin{array}{c}\text { Previous CABG } \\
\text { interval }(\mathbf{y})\end{array}$ & EuroSCORE & $\begin{array}{l}\text { Patent graft } \\
\text { anterior wall }\end{array}$ & $\begin{array}{c}\text { Grafted } \\
\text { vessel }\end{array}$ & $\begin{array}{l}\text { Follow-up } \\
(y)\end{array}$ & MACCE & $\begin{array}{c}\text { Exercise } \\
\text { stress test }\end{array}$ & $\begin{array}{c}\text { Exercise stress test } \\
\text { interval (y) }\end{array}$ \\
\hline 1 & 59 & 1 & 12 & 3 & LITA-LAD & PDA & 11.3 & No & Negative & 10.2 \\
\hline 2 & 53 & 1 & 11 & 3 & LITA-D-LAD & RCA & 10.9 & No & Negative & 9.9 \\
\hline 3 & 75 & 1 & 16 & 9 & LITA-D-LAD & PDA & 8.9 & No & - & - \\
\hline 4 & 75 & 1 & 11 & 8 & SVG-D-D-LAD & PDA & 8.4 & PCI & Negative & 4.7 \\
\hline 5 & 69 & 2 & 14,6 & 10 & LITA-LAD & PDA & 7.7 & No & - & - \\
\hline 6 & 73 & 1 & 18 & 6 & LITA-LAD & PDA & 7.6 & No & Negative & 2.4 \\
\hline 7 & 72 & 1 & 11 & 7 & SVG-D-LAD & PDA & 3.2 & Stroke, death & Negative & 0.2 \\
\hline 8 & 58 & 1 & 9 & 4 & LITA-D-LAD & RCA & 7.4 & No & - & - \\
\hline 9 & 55 & 1 & 5 & 9 & LITA-LAD & PDA & 7.2 & No & Negative & 5.2 \\
\hline 10 & 62 & 1 & 11 & 7 & LITA-D-LAD & PDA & 7.1 & No & Negative & 1.8 \\
\hline 11 & 58 & 1 & 10 & 6 & LITA-LAD & RCA & 7.0 & No & Negative & 6.8 \\
\hline 12 & 69 & 1 & 8 & 5 & LITA-D-LAD & SVG & 6.1 & PCI & Negative & 5.7 \\
\hline 13 & 51 & 1 & 15 & 5 & LITA-LAD & RCA & 2.0 & Death & Negative & 0.2 \\
\hline 14 & 67 & 1 & 7 & 13 & RITA-LAD & PDA & 5.9 & PCI & Negative & 0.2 \\
\hline 15 & 76 & 2 & 28,12 & 7 & LITA-LAD & PDA & 4.9 & No & - & - \\
\hline 16 & 53 & 1 & 1 & 4 & - & $\mathrm{RCA}$ & 2.0 & No & Negative & 0.3 \\
\hline 17 & 62 & 1 & 12 & 7 & LITA-D-LAD & RCA & 2.0 & No & - & - \\
\hline 18 & 61 & 1 & 13 & 4 & LITA-LAD & RCA & 1.5 & No & - & - \\
\hline 19 & 54 & 1 & 8 & 3 & LITA-LAD & PDA & 1.4 & No & Negative & 0.3 \\
\hline 20 & 69 & 1 & 4 & 7 & LITA-LAD & RCA & 0.3 & No & Negative & 0.3 \\
\hline 21 & 68 & 1 & 30 & 6 & SVG-LAD & PDA & 0.1 & No & - & - \\
\hline 22 & 70 & 1 & 16 & 7 & LITA-LAD & $\mathrm{RCA}$ & 0.1 & No & - & - \\
\hline
\end{tabular}

Pt, Patient; $C A B G$, coronary artery bypass grafting; $M A C C E$, major cardiovascular or cerebrovascular event; $L I T A$, left internal thoracic artery; $L A D$, left anterior descending artery; $P D A$, right posterior descending artery; $D$, diagonal branch; $R C A$, right coronary artery; $S V G$, saphenous vein graft; $P C I$, percutaneous coronary intervention; $R I T A$, right internal thoracic artery.

operation time was $172 \pm 34$ minutes. An intracoronary shunt was used in 11 patients. No hemodynamic instability or S-T segment changes on the electrocardiogram occurred during the operations. No conversion to sternotomy or the use of CPB occurred, and no intra-aortic balloon pump was required.

\section{Early Clinical Outcome}

There was no in-hospital mortality. The median time to extubation was 3.5 hours (range, 0-24). Two patients were extubated before leaving the operating room. No new myocardial infarction, defined as creatine kinase-MB isoform or troponin $\mathrm{T}$ level elevation (ie, $>3$ times the upper limit of normal or $>1 \mu \mathrm{g} / \mathrm{L}$, respectively) and new $\mathrm{Q}$ waves on the electrocardiogram, occurred. No blood transfusion was needed in 16 patients. In-hospital morbidity included pneumothorax needing drainage 1 day postoperatively in 1 patient and atrial fibrillation in 2 patients. The median duration of intensive care unit stay was 22 hours (range, 8-70). The median hospital stay was 5 days (range, 4-15).

\section{Mid-Term Clinical Outcome}

All patients complied with follow-up. The median follow-up time was 6.0 years (range, 0.1-11.3). There were 2 late deaths. One patient (patient 13, Table 1) died 2.0 years after the operation of septic shock consequent to pneumonia. The second patient (patient 7) died 3.2 years after surgery of an unknown cause. The estimated overall survival rate was $86.7 \%$ at 6 years (Figure 1, $A$ ). Four patients experienced recurrence of angina. Three of them underwent PCI. One patient (patient 14) developed acute coronary syndrome 6 months after the operation. At coronary angiography, the GEA was patent and PCI of the left anterior descending artery was performed. Another patient (patient 4) experienced recurrence of angina 1 year after the operation. Coronary angiography showed a "slender sign" of the GEA, and PCI of the RCA was eventually performed in combination with PCI of the left anterior descending artery. The third patient (patient 12) experienced recurrence of angina 5 years after the operation. In this patient, the target vessel for the GEA at repeat CABG had been a patent SVG bridge between the PDA and the posterolateral branch of the RCA. At angiography, the GEA was patent, but a stenosis in the recipient segment of the SVG distal of the anastomosis was found (Figure 2, A). PCI of the SVG was successfully performed throughout the GEA graft (Figure 2, B). The fourth patient with recurrence of angina (patient 8 ) experienced symptoms 5 years after surgery. At angiography, the GEA was patent (Figure 3), as were both ITAs. This patient was treated with medication. Two other patients without symptoms underwent follow-up coronary angiography at 3 and 5 years postoperatively (patients 3 and 2, respectively). In both patients, the GEA was patent. One patient had a stroke. MACCE occurred in 5 patients. 
TABLE 2. Demographics and preoperative characteristics

\begin{tabular}{lc}
\hline \multicolumn{1}{c}{ Variable } & Mean \pm SD or n $(\%)$ \\
\hline Demographics & \\
Age (y) & $64.5 \pm 8.1$ \\
Male gender & $21(95.5)$ \\
Coronary artery disease & \\
CCS angina III or IV & $15(68.2)$ \\
Previous MI & $13(59.1)$ \\
Previous PCI & $10(45.5)$ \\
Interval, previous operation (y) & $11.6 \pm 5.9$ \\
Comorbidities & \\
COPD & $3(13.6)$ \\
Hypertension & $12(54.5)$ \\
Hypercholesterolemia & $5(22.7)$ \\
Diabetes mellitus & $3(13.6)$ \\
Previous stroke & $2(9.1)$ \\
Craniocervical vascular disease & $2(9.1)$ \\
Peripheral arterial disease & $2(9.1)$ \\
Renal insufficiency & 0 \\
Obesity & $7(31.8)$ \\
EuroSCORE & \\
Additive & $6.4 \pm 2.5$ \\
Logistic & $7.9 \pm 6.8$ \\
\hline$S D$, standard deviation; $C C S$, Canadian Cardiovascular Society; $M I$, myocardial in- \\
farction; $P C I$, percutaneous coronary intervention; COPD, chronic obstructive pul- \\
monary disease.
\end{tabular}

The estimated freedom from MACCE rate was $70.2 \%$ at 6 years (Figure 1, B). Fourteen patients underwent one or more exercise stress tests with a median interval of 2.1 years (range, 0.2-10.2) between the repeat operation and the latest stress test. All latest stress tests were negative, without any sign of myocardial ischemia (Table 1).

\section{DISCUSSION}

To avoid cardiovascular injury at repeat $\mathrm{CABG}$ involving solely the RCA or PDA, a small laparotomy approach using the GEA has been previously reported to be an effective option. ${ }^{6-8}$ However, most of these procedures were performed with a T-shaped incision of the lower third of the sternum. This lower sternotomy using a T-shaped incision might be advantageous to gain sufficient exposure to the target vessel. ${ }^{8}$ However, it still requires a total transverse division of the sternum, which is associated with potential risks, such as injury to the heart and sternum nonunion, with subsequent pseudojoint formation. In this series of 22 redo patients, successful revascularization of the RCA or PDA using the GEA was established without any sternotomy. In our experience, no patients had inadequate exposure, and the RCA or the PDA was always easily accessible. The absence of in-hospital mortality and the negligible in-hospital morbidity confirm that the transabdominal approach is a safe procedure.

In general, we consider the GEA the graft of choice in patients in whom revascularization is limited to the right coronary system because of its position close to the inferior
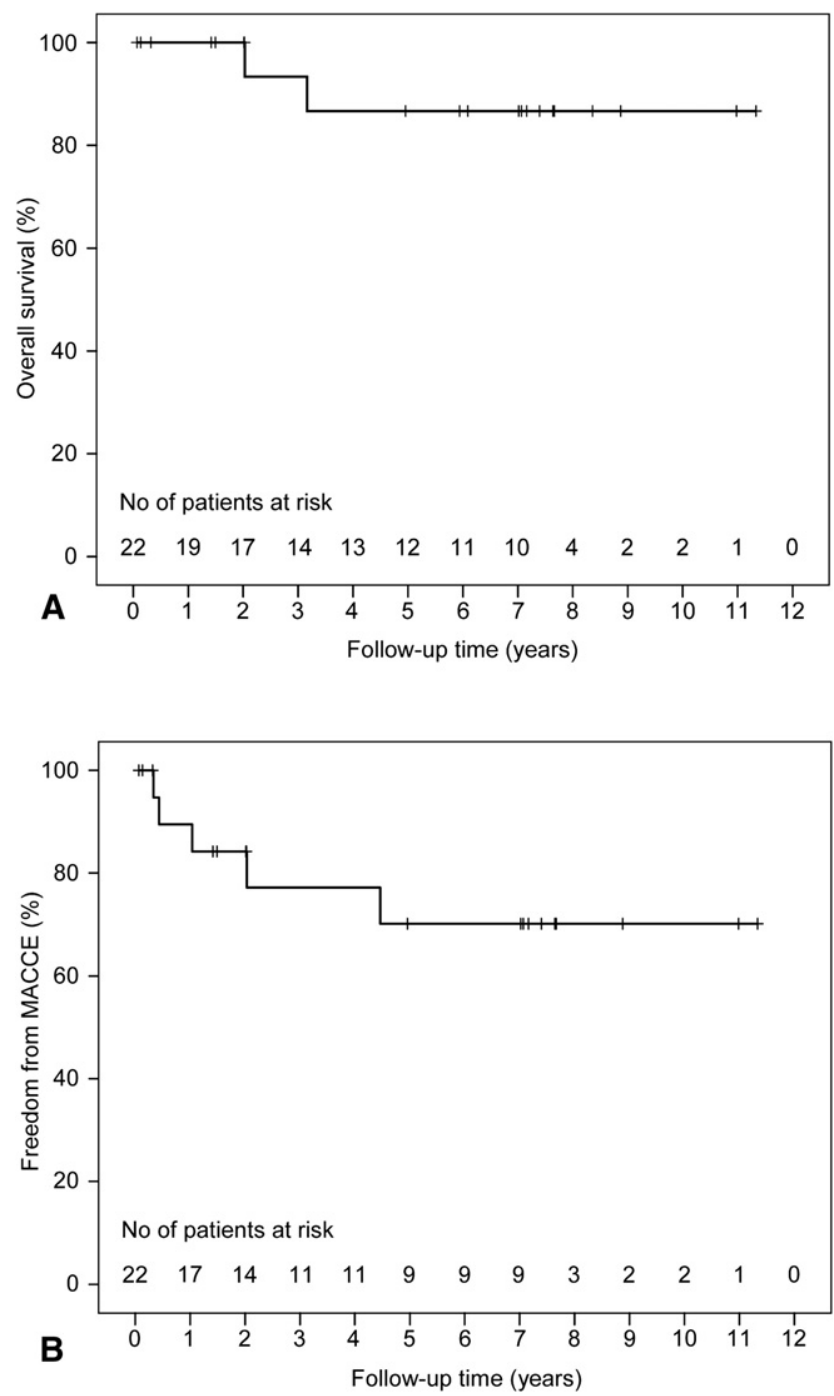

FIGURE 1. Kaplan-Meier estimates of event-free rates in patients reoperated on using the transabdominal approach without any sternotomy. A, Overall survival. B, Freedom from major cardiovascular and cerebrovascular events (MACCE).

wall of the heart. ${ }^{9}$ With the transabdominal approach, harvesting of the GEA can be easily performed through a small incision of 8 to $10 \mathrm{~cm}$ above the xiphoid. We prefer to harvest the GEA using the skeletonized technique. The visibility with the bare artery is much better compared with the GEA surrounded by a wide pedicle. This is especially important when performing the anastomosis in a small and deep space and might explain why we had sufficient exposure in all our patients. Because the GEA is a muscular artery prone to spasm, the skeletonization technique using the ultrasonic scalpel has two additional advantages. First, harvesting can be performed without vasospasm or injury to the artery. Second, the caliber size of the graft can be enlarged, assuring adequate flow capacity. ${ }^{10}$ In handling the GEA, intraluminal injection of a nitroprusside hydrochloride 

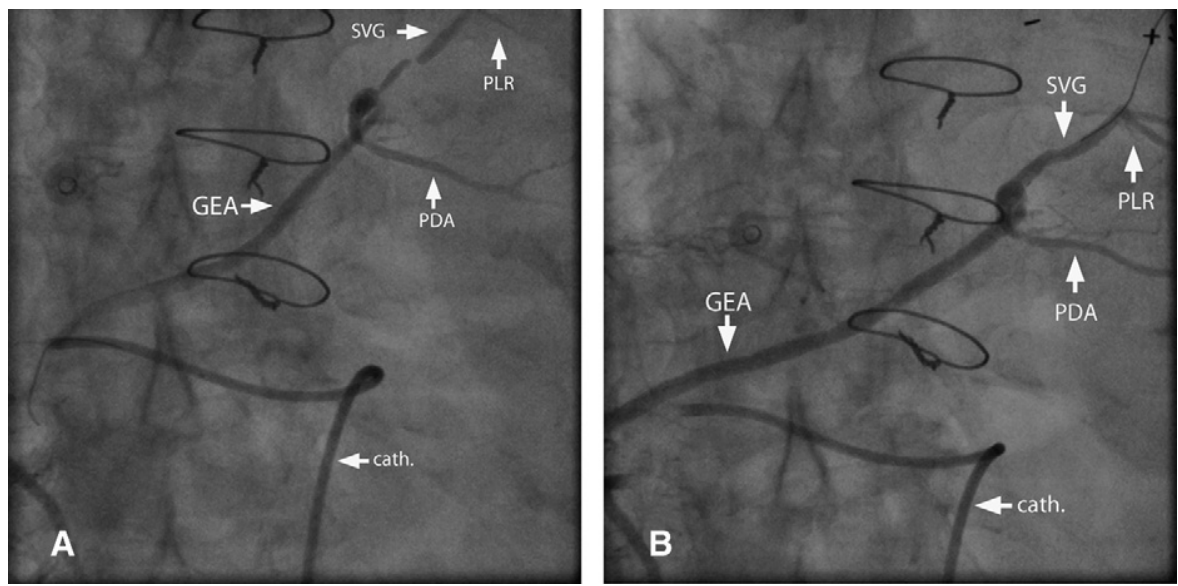

FIGURE 2. Angiographic views of the right gastroepiploic artery (GEA) 5 years after surgery (patient 12, Table 1). A, The GEA graft is patent but a stenosis in the recipient segment of the saphenous vein graft $(S V G)$ is present. B, Aspect after successful percutaneous coronary intervention of the SVG throughout the GEA. PDA, Posterior descending artery of the right coronary artery $(R C A) ; P L R$, posterolateral branch of the RCA; cath, angiographic catheter.

solution into the skeletonized graft and putting it in a warm gauze imbedded in dilute nitroprusside will help the artery to vasodilate further using both the pharmacologic effect of the nitroprusside and its own blood pressure.

We used the off-pump technique in conjunction with the transabdominal approach in all patients. The feasibility of using the GEA in repeat CABG on the beating heart by way of a median sternotomy has already been described in the 1990s ${ }^{11}$ However, its feasibility using minimal access techniques has been scarcely reported. ${ }^{6,7}$ Glineur and colleagues $^{8}$ reported successful off-pump repeat CABG

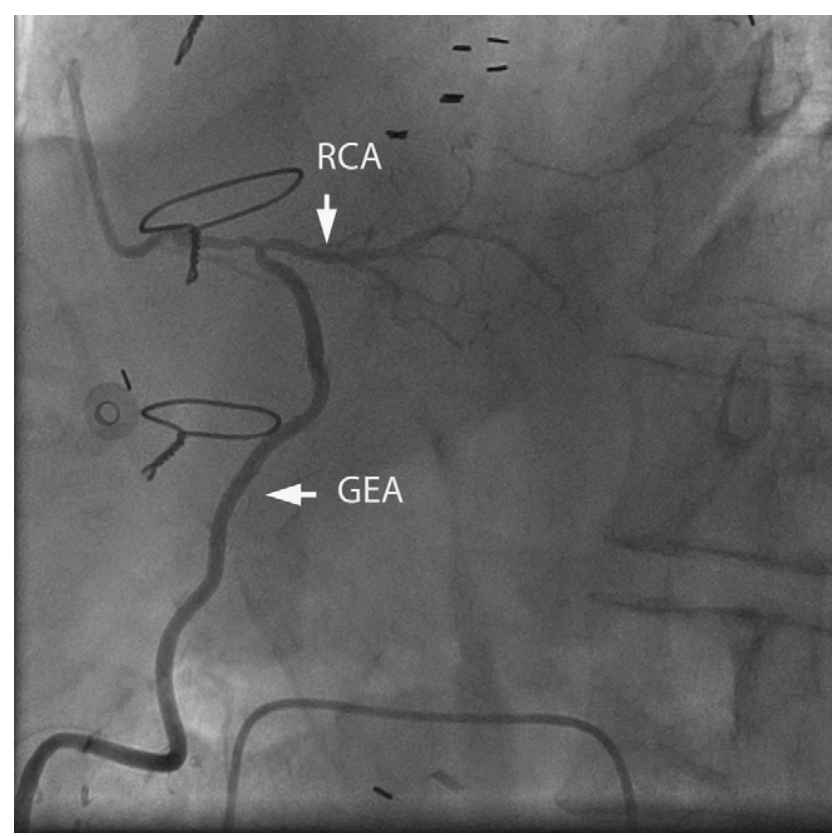

FIGURE 3. Angiography showing a patent right gastroepiploic artery (GEA) graft 5 years after surgery (patient 8 , Table 1). The GEA was anastomosed to the right coronary artery $(R C A)$. using the GEA without any sternotomy in 5 patients. From our experience involving a series of 22 patients, the transabdominal off-pump approach is a technically viable procedure in this setting. No patient required conversion to CPB. Also, this approach is easily applicable because it does not demand instruments other than those routinely used in off-pump CABG using a median sternotomy. Only in obese patients with a large anterior-posterior width of the chest might one encounter some technical difficulties. In such patients, longer instruments (ie, forceps, knife, scissors, needle holder) might be necessary. One might improve exposure in these patients by suturing the diaphragm to the caudal end of the skin incision or by placing a deep abdominal retractor, pulling caudally the diaphragm, liver, and other abdominal organs.

In this series, grafting to the RCA or the PDA was performed without negatively affecting the hemodynamics of the patients. In addition, although these were reoperations, surgery required a relatively short time, little need for blood transfusion, and modest postoperative management. The inhospital morbidity was limited to a pneumothorax in 1 patient and atrial fibrillation in 2 patients. Another attractive aspect of the transabdominal approach is that postoperative wound pain is low. Most of our patients, including the elderly patients, could walk around the ward without any assistance shortly after removal of the chest tubes. Overall, the hospitalization phase was impressively short, with a median hospital stay of 5 days.

With regard to the mid-term outcome, we found promising results. Both the estimated overall survival and estimated freedom from MACCE rates at 6 years were favorable ( $86.7 \%$ and $70.2 \%$, respectively). Of the 6 patients who were evaluated using coronary angiography, 5 showed the GEA graft to be patent and 1 patient showed a "slender sign" of the GEA. This is in accordance with 
earlier studies that described patent GEA grafts with the offpump technique in general ${ }^{10,12}$ or in conjunction with a minimal access technique. ${ }^{7,8}$ Notwithstanding this, some concern about the patency of the GEA when using a minimal access technique might exist. Fonger and colleagues ${ }^{13}$ reported both high mortality and high graft occlusion and stenosis rates early after minimally invasive direct coronary artery bypass grafting with the GEA. Importantly, however, their series differed from ours in that for revascularization of the RCA, a different route of the GEA was used. The GEA was brought anterior to the stomach and left lobe of the liver and directed over the diaphragm (ie, anterior routing of the GEA). We always routed the GEA through a small incision in the right hemidiaphragm to ensure adequate graft alignment with the target vessel to avoid kinking. In addition, Fonger and associates ${ }^{13}$ used pedicled GEA grafts instead of skeletonized grafts in their series.

From our experience, we consider the present technique to be both safe and effective. However, we understand that cardiothoracic surgeons might hesitate to apply this technique, because they might be either reluctant to enter the abdominal cavity or concerned about sufficient surgical exposure, or both. The personal learning curve for this series evolved from on-pump coronary revascularization with the GEA, to off-pump GEA revascularization with resternotomy, to off-pump GEA revascularization with minimal approaches. Having experience with on-pump coronary revascularization using the GEA since the early $1990 \mathrm{~s},{ }^{14}$ the first off-pump GEA revascularization was performed in 1994 in a redo case with a patent left internal thoracic artery on the left anterior descending artery that needed only RCA revascularization. At that time, resternotomy was performed. The sternum was minimally split to permit minimal dissection of the inferior wall of the heart to expose the RCA far enough to perform the anastomosis with the GEA. ${ }^{11}$ In 1998, two off-pump repeat CABGs with the GEA were performed using a transabdominal and a T-shaped low sternotomy approach. Since that time, the transabdominal technique without any sternotomy, such as was described in this report, has been successfully performed in all selected cases.

\section{CONCLUSIONS}

Repeat off-pump CABG using the GEA with the transabdominal approach is a feasible, safe, and effective procedure with low in-hospital mortality and morbidity and favorable mid-term results. However, some experience in using the GEA in repeat CABG on the beating heart is recommended.

\section{References}

1. Gillinov AM, Casselman FP, Lytle BW, Blackstone EH, Parsons EM, Loop FD, et al. Injury to a patent left internal thoracic artery graft at coronary reoperation. Ann Thorac Surg. 1999;67:382-6.

2. Byrne JG, Karavas AN, Filsoufi F, Mihaljevic T, Aklog L, Adams DH, et al. Aortic valve surgery after previous coronary artery bypass grafting with functioning internal mammary artery grafts. Ann Thorac Surg. 2002;73:779-84.

3. Park CB, Suri RM, Burkhart HM, Greason KL, Dearani JA, Schaff HV, et al. Identifying patients at particular risk of injury during repeat sternotomy: analysis of 2555 cardiac reoperations. J Thorac Cardiovasc Surg. 2010;140:1028-35.

4. De Oliveira SA, Lisboa LA, Dallan LA, Puig LB, Succi GM, Abreu Filho CA. Limited left thoracotomy for reoperative coronary artery bypass grafting without cardiopulmonary bypass for circumflex grafting in patients with patent internal thoracic artery graft. Heart Surg Forum. 2004;7:22-6.

5. Harris DG, Coetzee AR, Augustyn JT, Saaiman A. Repeat surgery for coronary artery bypass grafting: the role of the left thoracotomy approach. Heart Surg Forum. 2009; 12:E163-7.

6. Grandjean JG, Mariani MA, Ebels T. Coronary reoperation via small laparotomy using right gastroepiploic artery without CPB. Ann Thorac Surg. 1996;61: 1853-5.

7. Takahashi K, Minakawa M, Kondo N, Oikawa S, Hatakeyama M. Coronary artery bypass surgery by the transdiaphragmatic approach. Ann Thorac Surg. 2002; 74:700-3.

8. Glineur D, Noirhomme P, Poncelet A, Hanet C, Astarci P, Verhelst R, et al. Gastroepiploic artery minimally invasive grafting in reoperative patients with patent mammaries. Ann Thorac Surg. 2005;79:1606-9.

9. Tavilla G, van Son JAM, Verhagen AF, Smedts F. Retrogastric versus antegastric and histology of the right gastroepiploic artery. Ann Thorac Surg. 1992;53: 1057-61.

10. Kamiya H, Watanabe G, Takemura H, Tomita S, Nagamine H, Kanamori T. Skeletonization of gastroepiploic artery graft in off-pump coronary artery bypass grafting: early clinical and angiographic assessment. Ann Thorac Surg. 2004; 77:2046-50

11. Tavilla G, Pijls NHJ. Right gastroepiploic artery for coronary bypass reoperation without cardiopulmonary bypass. J Cardiovasc Surg. 1997;38:77-80.

12. Kim KB, Cho KR, Jeong DS. Midterm angiographic follow-up after off-pump coronary artery bypass: serial comparison using early, 1-year, and 5-year postoperative angiograms. J Thorac Cardiovasc Surg. 2008;135:300-7.

13. Fonger JD, Doty JR, Salazar JD, Walinsky PL, Salomon NW. Initial experience with MIDCAB grafting using the gastroepiploic artery. Ann Thorac Surg. 1999; 68:431-6.

14. Tavilla G, Kappetein AP, Braun J, Gopie J, Tjien AT, Dion RA. Long-term follow-up of coronary artery bypass grafting in three-vessel disease using exclusively pedicled bilateral internal thoracic and right gastroepiploic arteries. Ann Thorac Surg. 2004;77:794-9. 